\title{
Cervical Intramedullary Neurofibroma
}

\author{
Vivek Sharma, M.S., Goodwin Newton, M.S. \\ Department of Neurosurgery, King George's Medical College, \\ Lucknow, India.
}

\begin{abstract}
Intramedullary spinal neurofibroma is extremely rare. A case of cervical intramedullary neurofibroma is presented in a 21-year-old man. Only 20 case have been previousely reported in the literature. The site of origin is discussed with various hypotheses.
\end{abstract}

Key Words: Intramedullary neurofibroma, Spinal cord compression, Schwann cell

\section{INTRODUCTION}

\section{Neurofibroma} arises from the Schwann cells of the nerve fibers. These cells sheathe the axons from the point at which the latter penetrate the pia mater to their termination. Proximal to this point of penetration, there is devoid of Schwann cells. It is unusual to encounter an intramedullary location.

\section{CASE REPORT}

A 20-year-old man was admitted complaining of gradual progressive weakness in both upper limbs over a one-year period. He noticed a decrease of sensation on the medial aspect of both forearms. There was no history of fever, trauma, of root pain. Bladder and bowel functions were intact. He observed fasiculations in the right upper limb.

Clinical examination revealed bilateral atrophy in the small muscles of the hands and diminution of sensation in the distribution of $\mathrm{C}-8$ through $\mathrm{T}-1$ dermatomes. The posterior column sensations were impaired. Deep tendon reflexes were exaggerated, and plantars showed extensor response.

A plain X-ray of the cervical spine showed a widening of the spinal canal. An omnipaque myelogram suggested an intramedullary space-occupying lesion

Address for Correspondence: Vivek Sharma, The Department of Neurosurgery, King George's Medical College, Lucknow, 226003 , India.

Reprint request to: Vivek Sharma, The Department of Neurosurgery, King George's Medical College, Lucknow, 226003 , India. at C-7 (Fig. 1). Computed tomography confirmed an intramedullary tumor, but without further clue regarding the nature of the lesion (Fig. 2). A laminectomy from C-5 to $\mathrm{T}-1$ was performed, and a solid avascular tumor was excised piecemeal from the intramedullary compartment using extreme care to avoid damage to the adjoining normal neural tissue. The tumor was posteriorly placed. Histopathological examination rev-

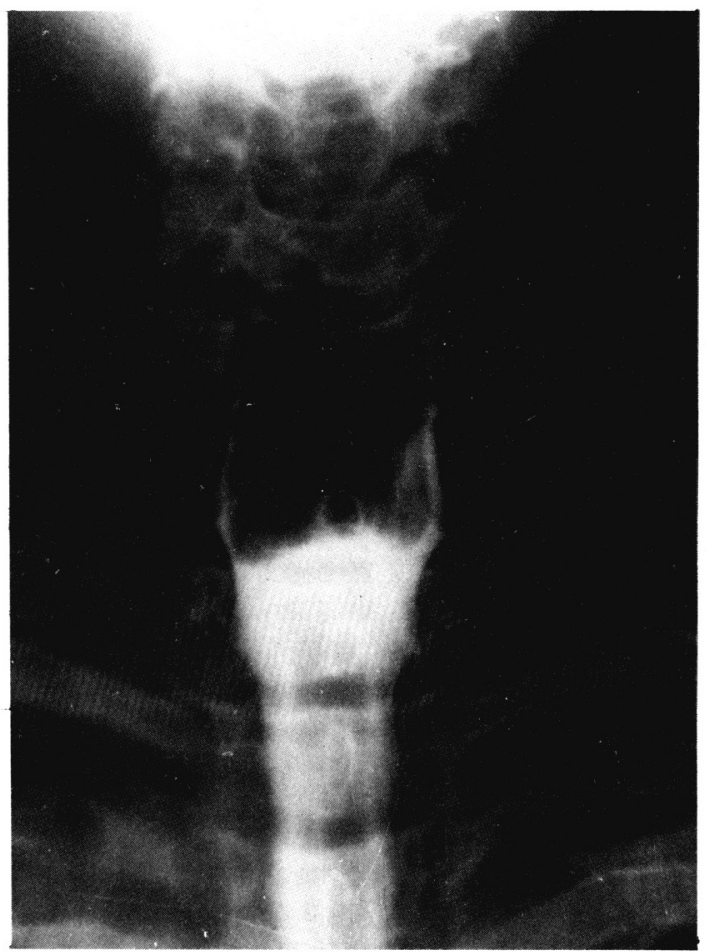

Fig. 1 Omnipaque myelogram suggestive of intramedullary space-occupying lesion in lower cervical area. 


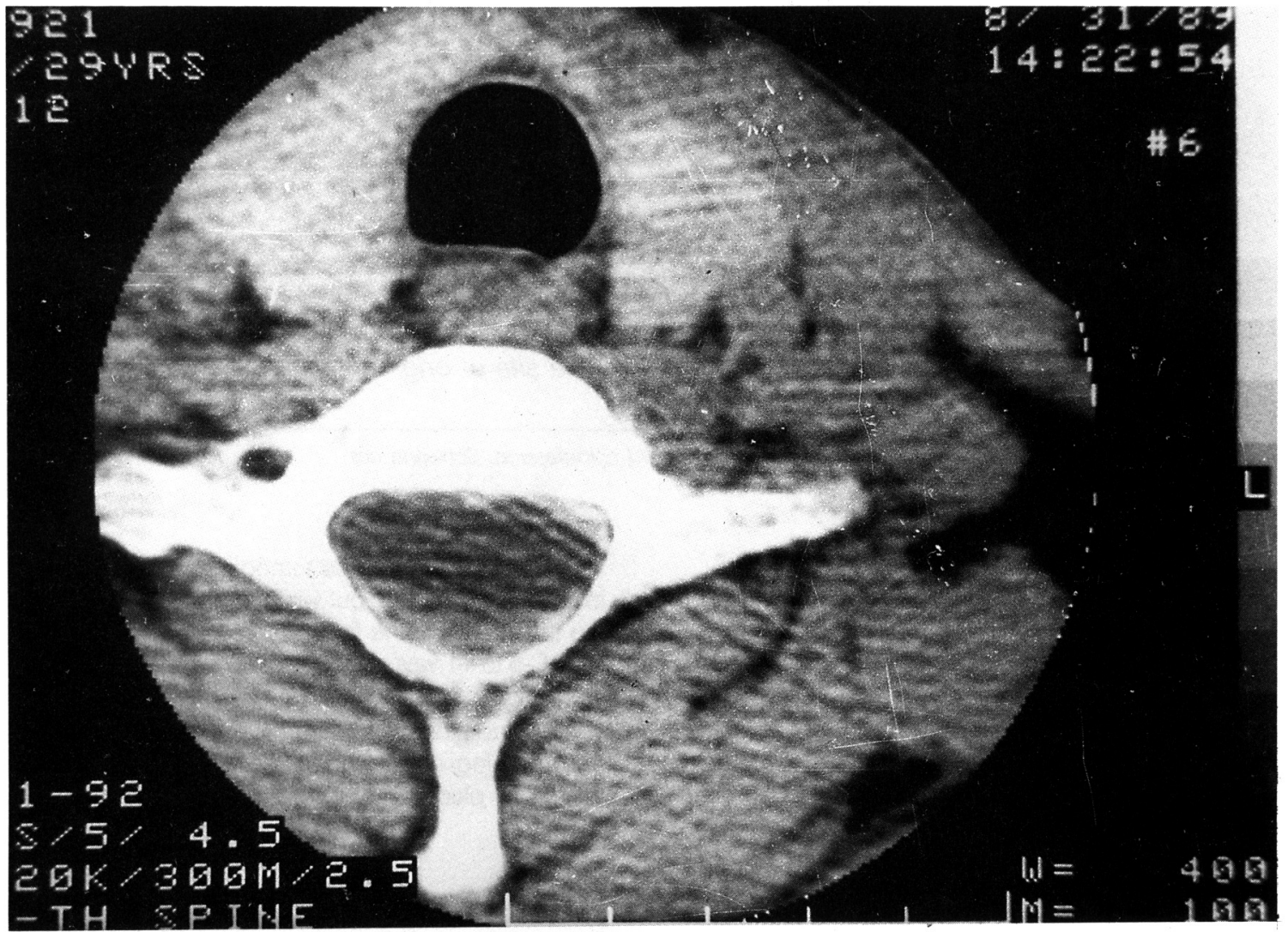

Fig. 2 CT myelography indicative of intramedullary lesion.

ealed the excised mass to neurofibroma (Fig. 3). Postoperative recovery was uneventful.

\section{DISCUSSION}

Intramedullary neurofibroma of the spinal cord is extremely rare because of the absence of Schwann cells proximal to the piamater. Since Riggs and Clary reported the first case in 1957, 20 cases have been reported in the literature (Riggs and Clary, 1957; Ramamurthi et al., 1958; Mason and Keigher, 1968; Koeppen et al., 1968; Wood et al., 1975; Vailati et al., 1979; Shalit and Sandbank, 1981; Rout et al., 1983). Various hypotheses have been postulated to find its site of origin, such as: (a) the presence of abnormal nerve plexuses accompanying the perforating branches of the ventral spinal artery within the perivascular spaces (Riggs and Clary, 1957); (b) a central displacement of Schwann cells during embryonic development (Ramamurthi et al., 1958; Vailati et al., 1979); (c) the presence of Schwann cells around the aberrant in- tramedullary nerve fibres (Koeppen et al., 1968); and (d) the transformation of pia cells of neuroectodermal origin into Schwann cells.

The sensory nerve roots selectively affected by neurofibroma, so they are commonly located at a posterior site (Wood et al., 1975). For this reason, clinical manifestations are few.

Analyzing all the reported cases sofar, cervical intramedullary neurofibroma is found most often in males in their third decade. In $60 \%$ of the cases, the cervical cord is involved. The usualy mode presentation is quadriparesis with urinary or rectal complaints. Among the cervical cases, it is the C-8 and T-1 segment which shows maximum involvement. $A$ plain $X$ ray and myelogram may be helpful in localizing the lesion, but they are unable to identify the nature of the lesion. Since neurofibroma is resistant to radiotherapy, the ideal mode of treatment would be its total excision(Wood et al,m 1975). Recurrence may be difficult to treat later on (Ramamurthi et al., 1958). If desirable, stage surgery may be advocated. 


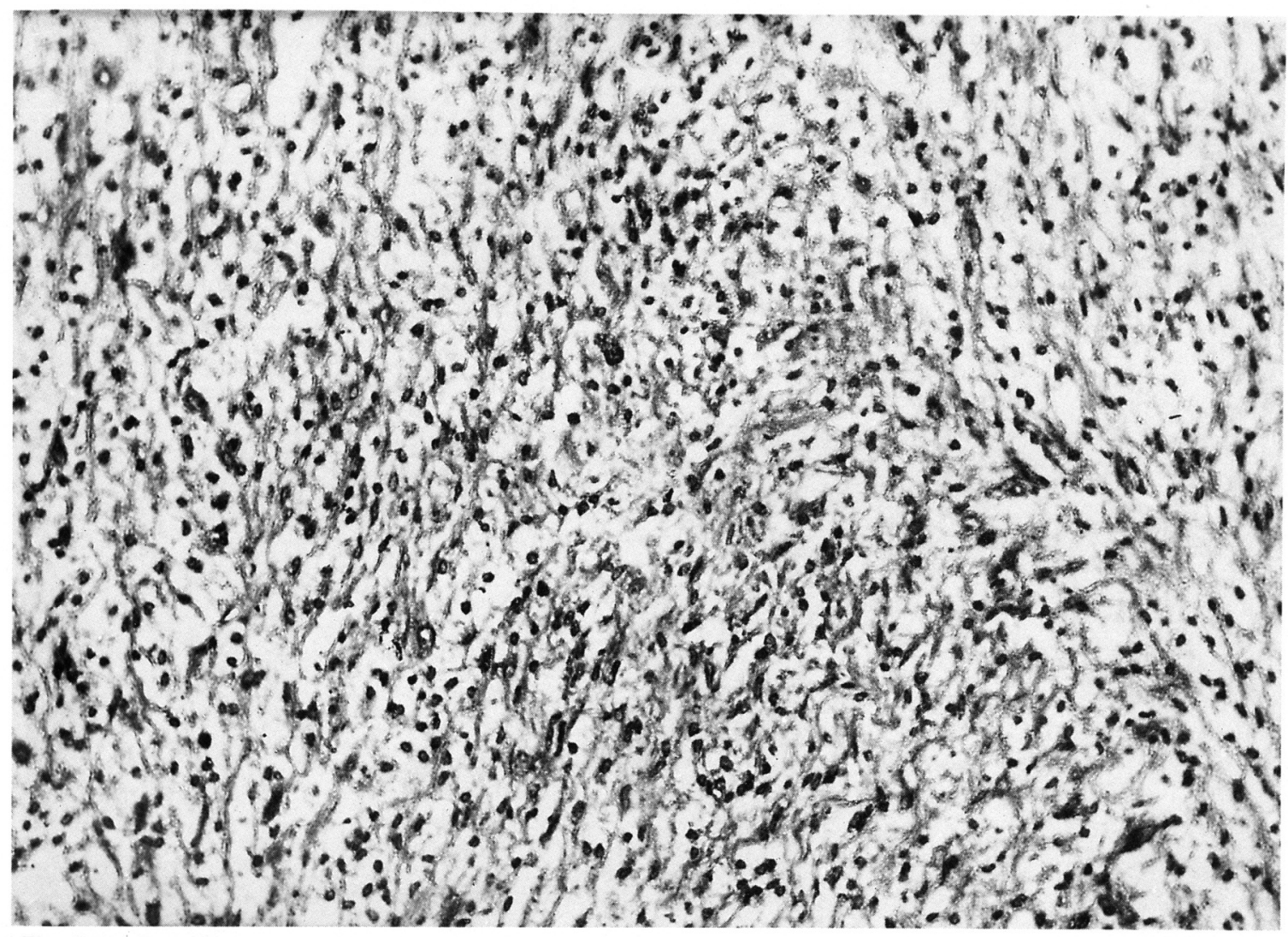

Fig. 3 Photomicrography showing lesion to be neurofibroma. (Haematoxylin and Eosin stain $\times 50$ ).

\section{REFERENCES}

Koeppen AH, Ordinario AT, Barron KD: Aberrant intramedullary peripheral nerve fibres. Arch Neurol 18:567-573, 1968.

Mason TH, Keigher HA: Intramedullary spinal neurilemmoma: Case report. J Neurosurg 36:414-416, 1968.

Ramamurthi B, Anguli VC, lyer CGS: A case of intramedullary neurinoma. J Neurol Neurosurg Psychiatry 21:92-04, 1958.

Riggs HE, Clary WU: A case of intramedullary sheath cell tumor of the spinal cord: consideration of vascular nerves as a source of origin. I Neuropathol Exp Neurol 16:332-336, 1957.

Rout D, Phillai SM, Radhakrishnan VV: Cervical intramedullary schwannoma: Case report. J Neurosurg 58:962-964, 1983.

Shalit MN, Sandbank U: Cervical intramedullary schwannoma, Surg Neurol 16:61-64, 1981.

Vailati G, Occhiogrosso M, Troccoli V: Intramedullary thoracic schwannoma. Surg Neurol 11:60-62, 1979.

Wood WG, Rothman LM, Nussbaum BE: Intramedullary neurilemmoma of the spinal cord: Case report. J Neurosurg 42:465-468, 1975. 